\title{
Effect of Gamma Irradiation and Vacuum Packaging on the Shelf Life Extension of Beef Kebab during Refrigerated Storage
}

\author{
M Shakhawat Hussain, MAkter Uzzaman, MAfazal Hossain, M Khorshed Alam, M Shamsul Islam* \\ and Roksana Huque
}

Microbiology \& Industrial Irradiation Division, Institute of Food \& Radiation Biology (IFRB), Atomic Energy Research Establishment (AERE), Ganakbari, Savar, GPO Box 3787, Dhaka 1000, Bangladesh

[Received 22 April 2006; Accepted 07 October 2006]

\begin{abstract}
Investigation was carried out on the shelf life extension of beef kebab by gamma irradiation and vacuum packaging stored at refrigeration temperature. On the basis of combined organoleptic, chemical and microbiological evaluation a dose of $5 \mathrm{kGy}$ and $2.5 \mathrm{kGy}$ extended the shelf life of beef kebabs more than 4 weeks and 2 weeks respectively than the unirradiated kebabs stored at refrigeration temperature. Vacuum packaging with and without gamma irradiation was found to have no effect on the shelf life extension of beef kebab.
\end{abstract}

Keywords: Beef kebab, Shelf life extension, Gamma irradiation, Vacuum packaging

Microbial contamination of meat leads to rapid spoilage and thus seriously affecting the consumer acceptance and economic loss ${ }^{1}$. During the process and storage, the meat is more prone to pigment and lipid oxidation, thus decreasing organoleptic qualities of the meat products and posing a major problem in the storing of convenient meat products and processes ${ }^{2-3}$. Food-borne infections involving meat products cause increased consumer awareness of possible contamination with pathogens ${ }^{4}$. As a result increased regularity controls have been introduced to ensure the safety of food. Chilled processed foods have been marked to satisfy the demand for convenient and fresh food products. However, such products could lead to new microbiological risk, problems related to certain pathogenic microorganisms that can multiply at chilled temperature ${ }^{5}$.

Irradiation is one possible method to help assure meat safety. The advantages of irradiation in controlling microorganisms in meat are well known ${ }^{1,6}$. It had been reported earlier ${ }^{5}$ that the shelf life of fish and fish kebab could be extended by irradiation and sun drying prior to storage at room temperature. This paper reports on the influence of irradiation and vacuum packaging prior to refrigeration storage on shelf life of beef kebab was investigated.

Beef kebab was prepared using the following ingredients: minced beef (2.5 kg), onion (300 g), eggs (4 pieces), chilli (8 pieces), black pepper powder (1 tea spoon), garlic (100 g), turmeric powder (1 tea spoon), table salt (2.5 tea spoon), cumin powder (2 tea spoon), clove powder (2 tea spoon), biscuit powder (300 g), flour (1 tea spoon) and tasting salt (1 tea spoon). After deep-frying in soybean oil, the kebab samples were sealed aseptically in presterilized (with $15 \mathrm{kGy}$ gamma irradiation) polyethylene pouches and divided into two sets, one with and another without vacuum packaging. Each set was further divided into three groups; one group of kebab was kept as control (without irradiation) and the second and the third groups were irradiated with gamma at 2.5 kGy and 5 kGy respectively. Irradiation was applied to the kebab samples from a ${ }^{60} \mathrm{Co}$ gamma source of $50 \mathrm{kCi}$ (present activity $25.08 \mathrm{kCi}$, dose rate $0.915 \mathrm{kGy} / \mathrm{h}$ ) located at Institute of Food and Radiation Biology (IFRB), AERE, Savar, Dhaka. The control and the irradiated samples were stored at refrigeration temperature $\left(6^{\circ}\right.$ to $8^{\circ} \mathrm{C}$ ) for quality assessment.

For quality assessment of the kebab samples stored at refrigeration temperature, chemical, microbiological and organoleptic parameters were monitored periodically. Thiobarbitaric acid (TBA) and free fatty acid (FFA) values of the kebab samples were estimated at different stages. These parameters were taken as the chemical indices of freshness for the beef kebab. TBA was determined by the method of Tarladgis et al. ${ }^{7}$. The FFA value was estimated according to the method of Pearson ${ }^{8}$. The microbiological counts of the samples were determined by using the decimal dilution technique followed by standard spread plate count ${ }^{9}$ using nutrient agar (Scharlau, Barcelona, Spain) for total bacterial counts and potato dextrose agar (Scharlau, Barcelona, Spain) for total fungal counts. Sensory evaluation of the shelf life of beef kebab was carried out using oranoleptic test scored on a 9 point hedonic scale as described

*Corresponding author:

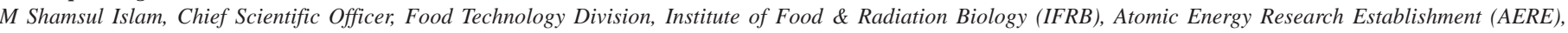
Ganakbari, Savar, GPO Box 3787, Dhaka 1000, Bangladesh

Tel (Office): (02) 7701831; Fax: +880 (02) 8613051; E-mail: ifrbft@dhaka.net 
by Miyauchi et al. ${ }^{10}$. The samples were judged by six judges for the overall acceptability and sensory properties, in terms of colour, odour, texture and taste.

Thiobarbitaric acid (TBA) values of unirradiated, irradiated and irradiated-vacuum packaged samples were found to increase with the prolongation of the storage time at refrigeration temperature (Figure 1). The values were found to be higher in irradiated samples than in unirradiated samples. Similar relationships between irradiated and unirradiated meat were also reported by Kwon et al. ${ }^{11}$. The TBA values have been commonly considered as an index of lipid rancidity. Gamma irradiation induces the oxidation of lipids especially the unsaturated lipid and produce lipid oxides. Subsequent decomposition of the unstable lipid oxides produces malonaldehyde. Increase of the TBA values during storage is due to the decomposition of the oxidized lipids ${ }^{12}$.

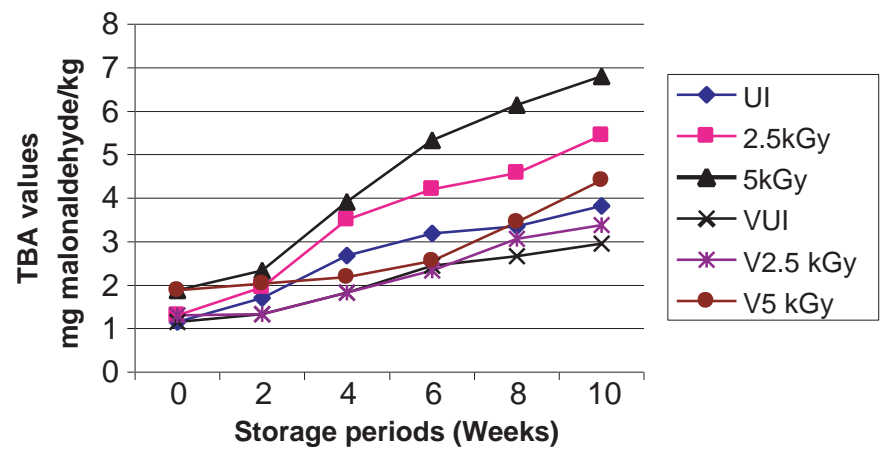

Figure 1. Thiobarbituric acid (TBA) value of irradiated and vacuum packaged beef kebab during refrigerated storage. $U I=$ Unirradiated; $2.5 k G y=$ Irradiated at $2.5 \mathrm{kGy} ; 5 \mathrm{kGy}=$ Irradiated at $5 \mathrm{kGy}$; VUI = Vacuum packaging and unirradated; V2.5 $k G y=$ Vacuum package and irradiated at 2.5 kGy; V5 $k G y=$ Vacuum package and irradiated at $5 k G y$

Figure 2 shows the free fatty acid (FFA) values of the samples at different storage times. The FFA value indicates the rancidity of the samples and, therefore, it might be a better index of freshness. The FFA values of unirradiated, irradiated and irradiated-vacuum packaged samples were found to increase with the storage period at refrigeration temperature. These values were found to be higher in unirradiated samples than in irradiated samples. The FFA values with all treatments were within acceptable limit up to 8 weeks. The results agree with the study of Choudhury et al. ${ }^{13}$.

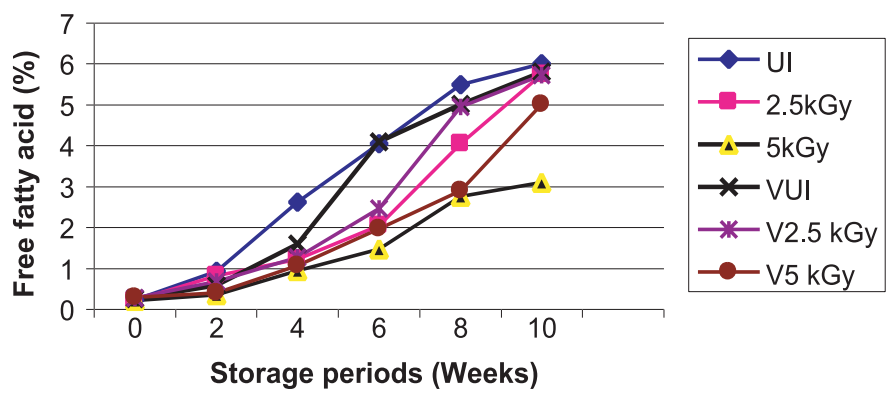

Figure 2. Free fatty acid (FFA) value of irradiated and vacuum packaged beef kebab during refrigerated storage. UI = Unirradiated; $2.5 \mathrm{kGy}=$ Irradiated at $2.5 \mathrm{kGy} ; 5 \mathrm{kGy}=$ Irradiated at $5 \mathrm{kGy} ; \mathrm{VUI}=$ Vacuum packaging and unirradated; V2.5 $k G y=$ Vacuum package and irradiated at $2.5 \mathrm{kGy}$; V5 $k G y=$ Vacuum package and irradiated at $5 k G y$

Table 1 summarizes the total bacterial count of irradiated and vacuum packaged beef kebab during refrigeration. It was found that the bacterial counts of the samples, with or without vacuum packaging, were greatly decreased by irradiation treatment. In addition, no viable fungal count was detected in the samples irradiated with 2.5 or $5 \mathrm{kGy}$ gamma radiation during the storage for 10 weeks (data not shown). The results clearly indicate that irradiation was very effective in reducing microbial loads. Niemand et al. ${ }^{13}$ reported that a total bacterial count of $10^{7} \mathrm{cfu} / \mathrm{g}$ of meat and meat products could be considered as the upper limit of microbiological acceptability. It was observed from this study that the microbial loads of the kebab samples, stored at refrigeration temperature with or without vacuum packaging, were within acceptable limit up to 2, 4 and 6 weeks respectively for unirradiated, $2.5 \mathrm{kGy}$-irradiated and $5 \mathrm{kGy}$-irradiated samples. According to $\mathrm{WHO}^{14}, \mathrm{FEHD}^{15}$ and $\mathrm{FSAI}^{16}$, a total bacterial count of $10^{5} \mathrm{cfu} / \mathrm{g}$ is considered as the acceptable limit for meat kebab, and the acceptable storage period specified is 4 weeks if the sample is

Table 1. Total bacterial count (cfu/g) of irradiated and vacuum packaged beef kebab during refrigerated storage

\begin{tabular}{lcccccc}
\hline Sample & \multicolumn{5}{c}{ Total bacterial count (cfu/g) at different storage period (Week) } \\
\cline { 2 - 6 } & 0 & 2 & 4 & 6 & 8 & 10 \\
\hline UI & $6.0 \times 10^{5}$ & $1.0 \times 10^{6}$ & $1.9 \times 10^{8}$ & $5.6 \times 10^{8}$ & Uncountable & Uncountable \\
$2.5 \mathrm{kGy}$ & $1.8 \times 10^{3}$ & $1.3 \times 10^{6}$ & $4.4 \times 10^{6}$ & $2.1 \times 10^{7}$ & $1.21 \times 10^{8}$ & $3.8 \times 10^{8}$ \\
$5 \mathrm{kGy}$ & $1.9 \times 10^{2}$ & $1.8 \times 10^{3}$ & $2.0 \times 10^{4}$ & $3.6 \times 10^{4}$ & $2.0 \times 10^{5}$ & $1.8 \times 10^{8}$ \\
VUI & $2.3 \times 10^{5}$ & $4.7 \times 10^{6}$ & $8.0 \times 10^{7}$ & Uncountable & Uncountable & Uncountable \\
V2.5kGy & $1.2 \times 10^{3}$ & $3.2 \times 10^{5}$ & $4.0 \times 10^{6}$ & $2.6 \times 10^{8}$ & $6.6 \times 10^{8}$ & $2.2 \times 10^{9}$ \\
V5kGy & $1.0 \times 10^{2}$ & $2.0 \times 10^{3}$ & $4.8 \times 10^{3}$ & $1.4 \times 10^{5}$ & $1.8 \times 10^{6}$ & $2.0 \times 10^{8}$ \\
\hline
\end{tabular}

$U I=$ Unirradiated; $2.5 \mathrm{kGy}=$ Irradiated at $2.5 \mathrm{kGy} ; 5 \mathrm{kGy}=$ Irradiated at $5 \mathrm{kGy} ; \mathrm{VUI}=$ Vacuum packaging and unirradated; V2.5 kGy = Vacuum package and irradiated at $2.5 \mathrm{kGy}$; V5 kGy = Vacuum package and irradiated at 5 kGy 
irradiated with $5 \mathrm{kGy}$ gamma radiation, with or with out vacuum packaging. On the basis of microbiological studies, it was observed in this study that vacuum packing had little influence on the extension of self-life of beef kebab.

Figure 3 shows the orgnaoleptic scores of kebab samples. It was observed that the unirradiated, $2.5 \mathrm{kGy}$-irradiated and $5 \mathrm{kGy}$ irradiated samples were orgnaoleptically acceptable respectively up to 4, 6 and 10 weeks storage at refrigeration temperature, no matter how they packaged, vacuum packaged or not. Miyauchi et $a l .{ }^{10}$ stated that the average sensory score of 5 might be acceptable. On the basis of organoleptic evaluation, it was found that the radiation dose of $5 \mathrm{kGy}$ and $2.5 \mathrm{kGy}$ could extend the shelf life of kebab for more than 5 and 2 weeks respectively.

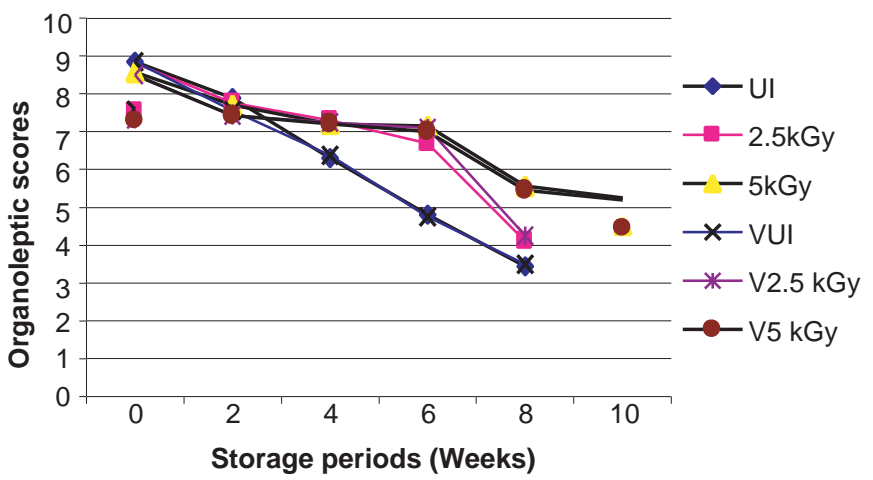

Figure 3. Organoleptic scores of irradiated and vacuum packaged beef kebab during refrigerated storage. UI = Unirradiated; $2.5 \mathrm{kGy}=$ Irradiated at $2.5 \mathrm{kGy} ; 5 \mathrm{kGy}=$ Irradiated at $5 \mathrm{kGy}$; VUI = Vacuum packaging and unirradated; V2.5 $k G y=$ Vacuum package and irradiated at $2.5 \mathrm{kGy}$; V5 $k G y=$ Vacuum package and irradiated at $5 k G y$

Kebab is a convenient ready-to-eat beef product, which is commercially prepared, hence the self-life extension and hygienic quality is very important for economic concern of traders and the safety of consumers. Irradiation could be effectively used for the shelf life extension and improving safety of such produces. In our present study, a dose of $5 \mathrm{kGy}$ and $2.5 \mathrm{kGy}$ extended the shelf life of beef kebab more than 4 weeks and 2 weeks respectively compared to the unirradiated samples stored at refrigeration temperature.

\section{References}

1. Fakhruddin ANM, Rashid H \& Choudhury N. 2003. Effect of acetic acid and temperature on bacteria associated with red meat. Bangladesh J Life Sci. 15(2): 79-84.

2. Pearson AM, Gray JI, Wolzak V \& Horenstein NA. 1983. Safety implication of oxidized lipids in muscle foods. Food Technol. 37: 121-129.

3. Verma SP \& Sahoo J. 2000. Effect of antioxidant vitamins on the quality of chevon sausage during refrigerated storage. J Food Sci Technol. 37(5): 493-499.

4. Luchsinger SE, Kropf DH, Garcia Zepeda CM, Hunt MC, Marsden JL, Rubio Canas EJ, Kastner CL, Kuecker WG \& Mata T. 1996. Colour and oxidative rancidity of gamma and electron Beam-irradiated boneless pork chops. J Food Sci. 61(5): 1000-1005.

5. Choudhury N, Siddique AK, Choudhury NA, Youssouf QM, Rashid H, Begum AA \& Alam MK. 1998. Preservation of semi-perishable food and development of convenience food using a combination of irradiation and other physicochemical treatments. Proceedings of of the Final Research Co-ordination Meeting of the International Atomic Energy Agency (IAEA), pp 77-96. IAEA, Vienna.

6. Sahoo J \& Anjaneyulu ASR. 2000. Effect of sodium ascorbate, alphatocopherol acetate and sodium tripolyphosphate on the quality of pre-blended ground buffalo meat. J Food Sci Techno. 37(4): 388-393.

7. Tarladgis BB, Watt BM, Younathan MT \& Dugan LR. 1960. A distillation method for quantitative determination of malonaldehyde in rancid food. $J$ Am Chem Soc. 37: 44-48.

8. Pearson D. 1976. The Chemical Analysis of Foods, $5^{\text {th }}$ edn, p 493. J\&A Charchill Ltd, London.

9. Sharp MS \& Lyles ST. 1969. Laboratory Instructions in Biology of Microorganisms, pp 23-25. The CV Mosley Co, St Louis.

10. Miyauchi DT, Eklund MW, Spinelli J \& Stall NV. 1964. Irradiation preservation of pacific coast shellfish, storage life of icing crabmeats at $33^{\circ} \mathrm{F}$ and $42^{\circ} \mathrm{F}$. Food Technol. 18: 677-681.

11. Kwon JH, Cho HO, Byun MW, Kim SW \& Yang JS. 1990. Application of irradiation techniques to food and foodstuffs. Research Report, 76/ 90:97. Korean Atomic Energy Research Institute, Seoul.

12. Alam MK, Hossain MA, Islam MS \& Hossain MM. 2005. Studies on the preservation of precooked and uncooked dehydrated beef by irradiation. Nucl Sci Appl. 14(2): 103-107 .

13. Niemand JG, Vander HJL \& Holzapfel HW. 1981. Radurization of prime beef cut. J Food Protect. 44: 677-681

14. WHO. 2002. Street foods in Accara, Ghana. In Bulletin of World Health Organization, Vol 80(7). World Health Organization, Geneva.

15. FEHD. 2001. Microbiological Guidelines for Ready-To-Eat Food, Risk Assessment Section, FEHD 66, pp 1-10. Food \& Environmental Hygiene Department, Queensway, Hong Kong.

16. FSAI. 2001. Guidelines for the Interpretation of Results of Microbiological Analysis of Some Ready-To-Eat Food Sampled at Point of Sale, Guidance Note No. 3, pp 15-16. Food Safety Authority of Ireland, Dublin 1. Available at: www.fsai.ie/publications/ guidance_note/gn3.pdf. Accessed February 12, 2006. 